\title{
Mejoramiento genético en trigo realizado por el INIFAP desde 1985 a 2020
}

\author{
Héctor Eduardo Villaseñor Mir ${ }^{1}$ \\ Julio Huerta Espino ${ }^{1}$ \\ Ernesto Solís Moya ${ }^{2}$ \\ María Florencia Rodríguez García ${ }^{1 \S}$ \\ Eliel Martínez Cruz ${ }^{1}$ \\ Eduardo Espitia Rangel ${ }^{1}$
}

${ }^{1}$ Campo Experimental Valle de México-INIFAP. Carretera Los Reyes-Texcoco km 13.5, Coatlinchán, Texcoco, México. CP. 56250. (villasenor.hector@inifap.gob.mx; huerta.julio@inifap.gob.mx; martinez.eliel@inifap.gob.mx; espitia.eduardo@inifap.gob.mx). ${ }^{2}$ Campo Experimental Bajío-INIFAP. Carretera Celaya-San Miguel de Allende km 6.5, Celaya, Guanajuato. (solis.ernesto@inifap.gob.mx).

${ }^{\S}$ Autora para correspondencia: rodriguez.maria@inifap.gob.mx.

\section{Resumen}

El mejoramiento genético de trigo en México inició en 1944, en el ahora denominado Campo Experimental Valle de México, bajo el mandato del Dr. Norman E. Borlaug. Sus investigaciones originaron las primeras variedades en 1948, que en la década de 1950's mostraron resistencia a la roya del tallo y en 1960's redujeron el porte de planta y generaron variedades que al sembrarse en África, India y Pakistán pusieron en marcha la 'Revolución Verde', impactos que galardonaron al Dr. Borlaug con el Premio Nobel de la Paz. En 1974 se diferenciaron tres programas de cruzamiento y selección: Noroeste, Bajío y temporal, el Centro Internacional de Mejoramiento de Maíz y Trigo, tiene mayor acción en el Noroeste, pero apoya a Bajío y temporal. Con la creación del Instituto Nacional de Investigaciones Forestales, Agrícolas y Pecuarias, éstos continuaron con su misión de liberar variedades. En 1993 se iniciaron trabajos con androesterilidad y en el 2000 se obtuvo un mutante androestéril dominante (Oly) que ha permitido el mejoramiento poblacional. Hasta 2020 han transcurrido 76 años y se han obtenido 154 generaciones de recombinación, ubicando al programa nacional entre los más dinámicos del mundo, con la contribución de más de 250 variedades: 140 liberadas por el INIFAP, que han sido base de la producción nacional, destacando Cirno C2008, sembrada en más de 1.5 millones de hectáreas la cual genera ingresos adicionales de \$6 700 millones. Los retos a corto plazo son incrementar la producción de grano en riego y fortalecer la investigación para el control de enfermedades, mayor eficiencia en el uso de agua, tolerancia a sequía y calor y calidad en grano, a mediano plazo controlar las royas e incrementar la siembra bajo riego reducido, a largo plazo incrementar la superficie sembrada en temporal, reducir pérdidas por enfermedades foliares, sequías, calor y liberar variedades con calidad nutricional.

Palabras claves: Triticum aestivum L., logros en mejoramiento genético, requerimientos a futuro.

Recibido: enero de 2021

Aceptado: abril de 2021 
A nivel mundial el trigo (Triticum spp.) es el cereal de mayor importancia después del maíz, su producción es principalmente para consumo humano (FAO, 2020). En México, durante 2018 destacó como el tercer cereal en importancia en cuanto a superficie sembrada (541 789 ha) (SIAP, 2019). Se prevé que para el 2050, la demanda de trigo aumentará un $70 \%$ debido al crecimiento de la población y los cambios en sus hábitos alimentarios.

En 1943 se estableció la Oficina de Estudios Especiales (OEE) en México y científicos norteamericanos llegaron a colaborar al Campo Experimental El Horno, ahora Campo Experimental Valle de México (CEVAMEX). En 1944 se realizan las primeras cruzas y se inició el mejoramiento continuo de trigo, que a la fecha realizan INIFAP y CIMMYT, trabajado dos ciclos agrícolas por año y en 2020 cumple 76 años (154 ciclos de recombinación y selección), ubicándose entre los más dinámicos en el mundo. Las aportaciones hasta 1985 se indican a continuación. La selección en invierno y verano (Borlaug, 1969), permitió fijar los genes Ppdl y Ppd2 insensibles al fotoperiodo (Rajaram, 1995).

La roya del tallo causada por Puccinia graminis f. sp. tritici se controló genéticamente en 1955, con el complejo Sr2 (Borlaug, 1969). Se incorporaron los genes Rht1 y Rht2 para menor altura de planta (Rajaram, 1995) y en los 1960's se liberaron 15 variedades enanas y semienanas que rindieron hasta $8 \mathrm{t} \mathrm{ha}^{-1}$ (Borlaug, 1969) algunas de éstas, al sembrarse en África, India y Pakistán pusieron en marcha la 'Revolución Verde', impactos que galardonaron al Dr. Borlaug con el Premio Nobel de la Paz y en 2014, al Dr. Sanjaya Rajaram Devi, con el Premio Mundial en Alimentación. En 1960 en el CAEVAMEX se instaló el laboratorio de calidad industrial de trigo y se generó una clasificación propia para las variedades harineras: gluten suave (S), medio (M), fuerte (F) y tenaz (T) (Villaseñor et al., 2009). A inicios de los 1970's el mejoramiento se realizó en: 1) INIA-CIANO y CIMMYT, en variedades de riego para el noroeste, norte y noreste; 2) INIA-CIAB, en variedades de riego para el Bajío; y 3) INIA-CIAMEC, en variedades para temporal (Villaseñor et al., 2009).

En los 1970’s y 1980's se realizó recombinación con trigos invernales y especies compatibles con Triticum lo que incorporó la translocación $1 B L / 1 R S$, que acarreó genes como $\operatorname{Lr} 26, \operatorname{Sr} 31, \operatorname{Yr} 9$ y Pm8 (Villareal, 1995), otros genes importantes también se incorporaron, como el complejo Lr13 (Rajaram et al., 1988), Lr34 y Lr46 (Huerta y Singh, 2000), todos éstos han permitido que las variedades mexicanas sean altamente rendidoras (Paquini-Rodríguez et al., 2016) de amplia adaptabilidad, resistentes a enfermedades (Huerta-Espino et al., 2020) y de calidad industrial.

\section{Creación del INIFAP y 35 años de investigación}

En 1985 el Instituto de Investigaciones Agrícolas (INIA) se reestructura y da origen al INIFAP y en el mejoramiento genético de trigo colaboraban 28 investigadores. A la fecha se han mantenido los tres programas, en los Campos Experimentales Valle del Yaqui (CEVY ahora CENEB), Bajío (CEBAJ) y Valle de México (CEVAMEX), cada uno con las misiones señaladas en los 1970's y con estrecha colaboración con el CIMMYT. La fortaleza lograda en el mejoramiento genético en trigo se debe a dos causas: 1) se han mantenido los principios de las estrategias implementadas entre los 1960's y 1980's, en torno a la forma de realizarlo, como rotar segregantes en ambientes contrastados, cumplir dos ciclos de selección al año, recombinar el germoplasma elite, incorporar continuamente variabilidad, utilizar metodologías de selección más prácticas, entre otras; y 2) dar mayor importancia a la evaluación de líneas experimentales en diversos años y ambientes. 
La generación de líneas la han realizado CIMMYT, INIFAP-CEVAMEX e INIFAP-CEBAJ, y su evaluación el INIFAP; a través, de la formación de ensayos nacionales y regionales evaluados anualmente hasta en 35 ambientes diferentes. También ha sido importante desde los 1990's, el apoyo obtenido a través de los proyectos nacionales financiados por INIFAP, CIMMYT, CONACYT, COFUPRO, SAGARPA-CONACYT, BIMBO, Mondelez y MASAGRO, que han permitido la continuidad del mejoramiento para liberar nuevas variedades (Villaseñor, 2015). En 35 años de fitomejoramiento se han mantenido las metodologías convencionales, a partir de 1993 se iniciaron trabajos para utilizar la esterilidad masculina para facilitar la selección recurrente (MSFRS) (Villaseñor et al., 2002; Villaseñor et al., 2015) y en los últimos años se han empleado herramientas moleculares para el pre-mejoramiento o para la generación de líneas uniformes (Juliana et al., 2020).

Las líneas de investigación para retroalimentar el mejoramiento genético son: 1) pérdidas causadas por royas; 2) identificación y distribución de las principales razas fisiológicas de los hongos causantes de royas; 3 ) análisis de la resistencia a royas; 4) postulación de genes y estudios genéticos de resistencia; 5) recombinación de genes de resistencia (Lr67) y de enanismo (Rht-D1); 6) introgresión de los genes $\operatorname{Yr} 5 a$ y $\operatorname{Yr} 15$; 7) análisis de la interacción Genotipo-Ambiente; 8) estudio de la calidad industrial; 9) obtención de un mutante androestéril dominante e incorporación del carácter en genotipos elite; 10) avance genético logrado por la MSFRS; 11) evaluación de pérdidas e identificación de resistencia a Zymoseptoria; 12) identificación de enfermedades foliares; 13) identificación del agente causal de la Fusariosis; 14) evaluación del avance genético; y 15) comparación del rendimiento de trigos harineros $v s$ trigos macarroneros.

En 2020, 17 investigadores e investigadoras colaboran en el programa de trigo de INIFAP, 11 menos que en 1985, pero la fortaleza de un trabajo bien coordinado, ha permitido poner a disposición de los agricultores 142 variedades en 35 años, la mayoría importantes en la producción nacional; como, CIRNO C2008 que en la última década se sembró en más de 1.5 millones de hectáreas, su mayor rendimiento, resistencia al acame y resistencia a las royas, ha originado ingresos adicionales para los agricultores por $\$ 6700$ millones.

Por otra parte, durante ese tiempo incontables estudiantes de licenciatura, maestría y doctorado han realizado sus prácticas y estancias de investigación, aunados a la obtención de tesis de grado, muchos de los cuales actualmente son docentes, investigadores del INIFAP o de otros centros de investigación. Además, de variedades y formación de recursos humanos, todos los integrantes de programa de trigo han hecho contribuciones a la ciencia con publicaciones técnicas y científicas mediante libros, capítulos de libro, artículos, resúmenes científicos, folletos y hojas desplegables.

\section{Retos a corto, mediano y largo plazo}

Los retos del programa de mejoramiento genético se sintetizan en mantener organizada y coordinadamente su continuidad para la generación de líneas, que, al evaluarse en los ensayos nacionales en ambientes y años, contrastantes, permitan liberar nuevas y mejores variedades. Para lograrlo es importante fortalecerlo con jóvenes investigadores y bajo los siguientes retos. A corto plazo incrementar la producción en riego vía mayor productividad y ampliación del área sembrada y fortalecer investigaciones sobre el control genético de enfermedades, riego reducido eficiencia en el uso del agua (EUA), tolerancia a sequía y calor y calidad nutricional. 
A mediano plazo, lograr el control genético de las royas, reducir las pérdidas causadas por enfermedades foliares e incrementar la producción en riego mediante la expansión del área bajo riego reducido. A largo plazo ampliar el área en temporal (ambientes de sequía) y en riego reducido bajo el sistema de labranza de conservación, controlar genéticamente las enfermedades y sembrar variedades tolerantes al estrés térmico y de mejor calidad nutricional, con la visión de producir alrededor de siete millones de toneladas.

\section{Conclusiones}

El futuro de la producción de trigo bajo condiciones de riego y temporal en México dependen del éxito de los programas en el desarrollo de variedades con mayor potencial de rendimiento, resistencia duradera a las enfermedades, uso eficiente del agua, tolerancia a la sequía y al calor, mejor absorción de nutrientes y buena calidad industrial. Estas variedades sembradas con manejo agronómico adecuado y paquetes tecnológicos óptimos, permitirán al agricultor producir trigo rentable, al industrial abastecerse de grano de buena calidad a precio competitivo y al consumidor surtir sus necesidades con productos a buen precio y de mejor calidad.

\section{Literatura citada}

Borlaug, N. E. 1969. Mejoramiento de trigo, su impacto en el abastecimiento mundial de alimentos. Sobretiro No. 2. Centro Internacional de Maíz y Trigo (CIMMYT). El Batán, Texcoco. Estado de México. 40 p.

FAO. 2020. Food and Agriculture Organization of the United Nations. Crops. Rome, Italy. http://www.fao.org/faostat/en/\#data/QC.

Huerta-Espino, J. y Singh, R. 2000. Las royas del trigo. In: el trigo de temporal en México. Villaseñor, M. H. E. y Espitia, E. (Ed.). Chapingo, Estado de México, México, SAGAR, INIFAP, Campo Experimental Valle de México. Libro técnico núm. 1. 231-251 pp.

Huerta-Espino, J.; Singh, R.; Crespo-Herrera, L. A.; Villaseñor-Mir, H. E. Rodríguez-García, M. F.; Dreisigacher, S.; Barcenas-Santana, D. and Lagudah E. 2020. Adult plant slow rusting genes confer high levels of resistance to rust in bread wheat cultivars from Mexico. 11:824. https://doi.org/10.3389/fpls.2020.00824.

Juliana, P.; Singh, R. P.; Huerta-Espino, J.; Bhavani, S.; Randhawa, M. S.; Kumar, U.; Joshi, A. K.; Bhati, P. K.; Villaseñor, M. H. E.; Mishra, Ch. N. and Singh, G. P. 2020. Genome-wide mapping and allelic fingerprinting provide insights into the genetics of resistance to wheat stripe rust in India, Kenya and Mexico. Sci. Rep. 10:10908. https://doi.org/10.1038/ s41598-020-67874-X.

Paquini-Rodríguez, S. L.; Benítez-Riquelme, I.; Villaseñor-Mir, H. E.; Muñoz-Orozco, A. y Vaquera-Huerta, H. 2016. Incremento en el rendimiento y sus components bajo riego normal y restringido de variedades mexicanas de trigo. Rev. Fitotec. Mex. 39(4):367-378.

Rajaram, S. 1995. Wheat germoplasm improvement: historical perspectives, philosophy, objectives, and missions. In: wheat breeding at CIMMYT: commemorating 50 years of research in Mexico for global wheat improvement. Rajaram, S. G. and Hettel P. (Ed.). Wheat Special Report No. 29. México, DF. Centro Internacional de Maíz y Trigo (CIMMYT). 1-10 pp.

Rajaram, S.; Singh, R. P. and Torres, E. 1988. Current CIMMYT approaches in breeding wheat for rust resistance. In: breeding strategies for resistance to the rust of wheat. Simmonds, N. W. Rajaram, S. (Ed.). México, DF. Centro Internacional de Maíz y Trigo (CIMMYT). 101$118 \mathrm{pp}$. 
SIAP. 2019. Servicio de Información Agroalimentaria y Pesquera. Producción Agroalimentaria y Pesquera. https://www.gob.mx/siap/.

Villarreal, R. L. 1995. Expanding the genetic base of CIMMYT bread wheat germoplasm. In: wheat breeding at CIMMYT: commemorating 50 years of research in Mexico for global wheat improvement. Rajaram, S. and Hettel, G. P. (Ed.). Wheat Special Report No. 29. México, DF. Centro Internacional de Maíz y Trigo (CIMMYT). 16-21 pp.

Villaseñor, M, H. E.; Castillo, G. F.; Espitia, R. E.; Rajaram, S. y Molina, G. J. D. 2002. Perspectivas del uso de la androesterilidad en el mejoramiento por selección recurrente de trigo en México. Rev. Fitotec. Mex. 25(3):321-326.

Villaseñor, M. H. E.; Huerta, E. J.; Pérez, H. P.; Rodríguez, G. M. F.; Martínez, C. E.; Hortelano, S. R. R. y Espitia, R. E. 2009. La investigación de trigo en el Campo Experimental Valle de México: historia y aportaciones. Reseña histórica 66 años al servicio de México 19432009. Pub. Esp. 1:29-31.

Villaseñor, M. H. E.; Hortelano, S. R. R.; Martínez, C. E.; Huerta, E. J.; García, L. E. y Espitia, R. E. 2015. Uso de la androesterilidad genética masculina en la reconversión de genotipos para realizar selección recurrente en trigo. Rev. Mex. Cienc. Agríc. Pub. Esp. 11:2177-2182.

Villaseñor, M. H. E. 2015. Sistema de mejoramiento genético de trigo en México. Rev. Mex. Cienc. Agríc. Pub. Esp. 11:2183-2189. 